\title{
BMJ Open Undergraduate medical students' behavioural intentions towards medical errors and how to handle them: a qualitative vignette study
}

\author{
Isabel Kiesewetter, ${ }^{1}$ Karen D Könings, ${ }^{2}$ Moritz Kager, ${ }^{3}$ Jan Kiesewetter ${ }^{3}$
}

To cite: Kiesewetter I, Könings KD, Kager M, et al. Undergraduate medical students' behavioural intentions towards medical errors and how to handle them: a qualitative vignette study. BMJ Open 2018;8:e019500. doi:10.1136/ bmjopen-2017-019500

- Prepublication history for this paper is available online. To view these files, please visit the journal online (http://dx.doi org/10.1136/bmjopen-2017019500).

Received 10 September 2017

Revised 3 January 2018

Accepted 23 January 2018
Check for updates

${ }^{1}$ Department of Anaesthesiology, Klinikum der Universität München, Munich, Germany ${ }^{2}$ Department of Educational Development and Research, Faculty of Health, Medicine and Life Sciences, School of Health Professions Education, Maastricht University,

Maastricht, Limburg, The Netherlands

${ }^{3}$ Institut für Didaktik und

Ausbildungsforschung in der

Medizin, Klinikum der Universität

München, München, Germany

Correspondence to

Dr Jan Kiesewetter;

Jan.Kiesewetter@med.Imu.de

\section{ABSTRACT}

Objectives In undergraduate medical education, the topics of errors in medicine and patient safety are under-represented. The aim of this study was to explore undergraduate medical students' behavioural intentions when confronted with an error

Design A qualitative case vignette survey was conducted including one of six randomly distributed case scenarios in which a hypothetical but realistic medical error occurred. The six scenarios differed regarding (1) who caused the error, (2) the presence of witnesses and (3) the consequences of the error for the patient. Participants were asked: 'What would you do?". Answers were collected as written free texts and analysed according to qualitative content analysis.

Setting Students from German medical schools participated anonymously through an online questionnaire tool.

Participants Altogether, $n=159$ students answered a case scenario. Participants were on average 24.6 years old $(S D=7.9)$ and $69 \%$ were female. They were undergraduate medical students in their first or second year $(n=27)$, third, fourth or fifth year $(n=107)$ or final year $(n=21)$.

Results During the inductive coding process, 19 categories emerged from the original data and were clustered into four themes: (1) considering communication; (2) considering reporting; (3) considering consequences; and (4) emotional responsiveness. When the student him/herself caused the error in the scenario, participants did mention communication with colleagues and taking preventive action less frequently than if someone else had caused the error. When a witness was present, participants more frequently mentioned disclosure of the error and taking actions than in the absence of a witness. When the outcome was significant to the patient, participants more often showed an emotional response than if there were no consequences.

Conclusions The study highlights the importance of coping strategies for healthcare professionals to adequately deal with errors. Educators need to introduce knowledge and skills on how to deal with errors and emotional preparedness for errors into undergraduate medical education.

\section{INTRODUCTION}

Concerning medical errors and patient safety, physicians take a central role in the

\section{Strengths and limitations of this study}

- This study is one of the first examining medical students' behavioural intentions towards medical errors using qualitative methods.

- Case vignettes are shown to be a useful method to investigate influences on behavioural intentions.

- How the students would actually behave in the case vignettes' situations is not part of this research.

- The relationship between behavioural intentions and actual behaviour in the context of medical error is not investigated in this study and needs to be the focus of future research.

- Participants represented a sample of German medical students, thus the results must be transferred with caution when applied to different settings or target groups.

healthcare system. On the one hand, physicians can prevent errors, ensure patient safety and follow-up on errors to prevent further harm. On the other hand, they also can generate errors, near misses and preventable adverse events. Physicians have complex tasks in stressful, error-prone situations ${ }^{1}$ and have to deal with the consequences of errors ${ }^{2}$ or near misses. ${ }^{3}$ Additionally, physicians themselves might be affected by an error and, as a 'second victim', can also be traumatised and suffering from the error. ${ }^{4}$ In recent years, the importance of developing skills to deal with medical errors for all professions in the healthcare setting has become clear. ${ }^{5-7}$ Although various international committees have demanded the early integration of medical error and patient safety educational structures for medical professionals,${ }^{8-10}$ thus far, there are very few international publications describing implemented formats for undergraduate medical education. ${ }^{11}$ In Germany, where the sample of the present study is taken from, there only exist a few of those structures with little consistency. ${ }^{12}$ 
Table 1 Case description and overview of the six possible scenarios

Case for all participants:

An elderly woman arrives in the emergency room because she has fallen.

She is having difficulties with the right hip, where a large haematoma is visible. Incorrectly, an X-ray of the left hip is being taken.

What would you do?

Negative patient outcome

I, myself, caused the error and there were no witnesses.

I, myself, caused the error and a colleague was witness.

I, myself, am the witness and a colleague caused the error.
Scenario 1

Scenario 2

Scenario 3
No consequences for patient

Scenario 4

Scenario 5

Scenario 6

Note. Example: Scenario 4-You are the attending physician who made this error. However, this was not witnessed by anyone. After 1 week, the patient comes in for a follow-up. This time the correct side is being X-rayed. The patient is pain-free and the X-ray does not indicate any pathology.

When new educational structures are developed, the students' attitude towards the topic of teaching has to be taken into account. ${ }^{13}$ While there are studies exploring the residents or physicians in training's attitudes concerning medical errors, ${ }^{14-16}$ only a few studies about students' attitudes towards medical errors exist. ${ }^{1718}$ By using quantitative approaches, some studies have shown that first-year medical students' attitudes support an error-friendly environment and state that they would disclose errors and do everything they can to ensure patient safety. ${ }^{19}{ }^{20}$ But, if an error would happen to them, students have limited knowledge about what to do and they also feel uncertain about how to handle the situation if a colleague had made an error. ${ }^{11}$ Most of the recent studies investigating the attitudes of medical students focus on the occurrence of disclosure, emotions and the fear of malpractice litigation. ${ }^{21}$

Martinez and $\mathrm{Lo}^{22}$ conducted a study examining medical students' experiences with medical errors by analysing anonymous descriptions of medical errors they had committed or witnessed. They show that many medical students had made or observed significant errors, and that students experienced severe distress and uncertainty. Moreover, in the population of this study, students reported high motivation to disclose the error to patients and to take responsibility.

Understanding undergraduate medical students' behavioural intentions could be another approach to investigating this very sensitive subject and to leave aside the pressing ethical issues emerging when discussing actual cases. Behavioural intentions are defined as the hypothetical actions people intend to choose in a specific event and have been concluded to be a valid proxy measure for behaviour among clinicians. ${ }^{23}$ A study by Muller and Ornstein ${ }^{24}$ investigated how students would feel after committing a hypothetical error and showed that feelings depended on the outcome to the patient. The more harmful the outcome was, the angrier the students would be towards themselves, the guiltier they would feel and the more afraid they would be of accusations and malpractice charges. Hence, factors such as the outcome of the patient after an error and the role or responsibility of the student (ie, being a witness or being the person who has made the error) may essentially influence the underlying behavioural intentions as well. However, in their study, it remained unclear what the students would actually $d o$ after committing an error, which will be the focus of our study.

Scientific approaches to describe attitudes and to understand behaviour or behavioural intentions are mainly based on qualitative research. In both medical studies and medical education research, qualitative research methods have been recognised as complementary and essential. Qualitative research intends to understand how people experience the world and seeks to reveal the underlying what and how of people's perceptions. $^{25}$

The main objective of the present case vignette study was to generate a basic comprehension of how undergraduate medical students deal with errors and to understand their behavioural intentions towards the topic. A qualitative research method was chosen to address the following research questions:

1. What kind of behavioural intentions do students express when they participate in a case with a medical error?

2. How do these behavioural intentions depend on factors such as the consequences for the patient, the presence of witnesses and their own role in committing error?

\section{METHODS}

\section{Participants and setting}

The survey was conducted using the online survey system Unipark (http://www.unipark.de/). The participants were recruited via email. All 38 German medical student councils forwarded the link to an online questionnaire via their mailing lists. All data were collected anonymously and the students' agreement to analyse the data was obtained before starting with the questionnaire. Participation was voluntary and those who participated took part in a lottery for book vouchers (10 vouchers with a value of $€ 20$ ). The online survey was filled out from a private computer and participants never came into personal contact with the researchers. 


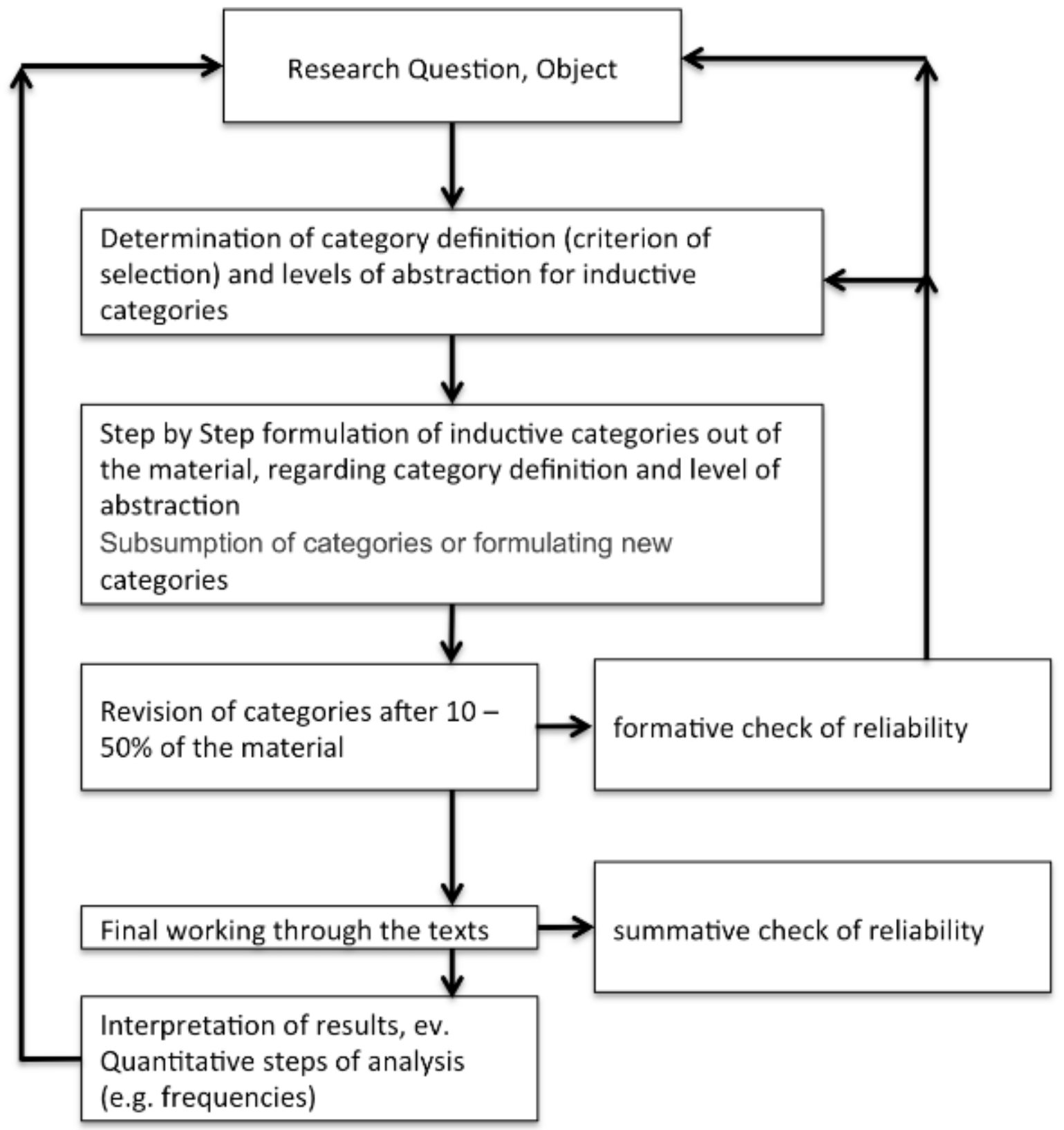

Figure 1 Step model of inductive category development according to Mayring and Fenzl. ${ }^{52}$

Each participant received one case scenario about a medical error, unaware that there were other versions. Six different cases (see the Materials section, table 1) were randomly distributed among the participants. Participants received a short, written introduction and the instruction to answer one open question. Another completely independent part of the questionnaire contained demographic data and quantitative data that are published elsewhere. ${ }^{26}$

The ethics committee of the responsible medical faculty approved this survey (ethical approval number UE036-13). The study was partly funded by a Volkswagen Foundation grant.

\section{Materials}

Six different scenarios of a case vignette about a hypothetical, but realistic situation dealing with a medical error were developed (see table 1). The case vignette had been developed by the second author and an internist at Maastricht University Medical Centre and six scenarios were created based on the original idea from Van Mierlo $e t a l .^{27}$ The six scenarios were tested in the Netherlands ${ }^{28}$ and translated into German for the present study. The scenarios were then piloted within 1 week on $\mathrm{n}=22$ medical students, who commented on the functionality and comprehensibility of the scenarios. Data from piloting were not included in this study. 
Table 2 Excerpt of the coding scheme

\begin{tabular}{|c|c|c|c|}
\hline Unit of analysis/quote & Paraphrase & Category & Coding rules and anchor examples \\
\hline \multirow{2}{*}{$\begin{array}{l}\text { Talk with a colleague and } \\
\text { point out to him that an error } \\
\text { has happened to him and } \\
\text { ask him how it might have } \\
\text { happened. I would also be } \\
\text { more cautious, so that those } \\
\text { things wouldn't happen to } \\
\text { me. In this case I wouldn't } \\
\text { disclose to the patient. } \\
\text { (No. } 28, \text { scenario 5) }\end{array}$} & $\begin{array}{l}\text { Point out to the } \\
\text { colleague that an error } \\
\text { has happened to him. }\end{array}$ & $\begin{array}{l}\text { Communication } \\
\text { with colleagues }\end{array}$ & $\begin{array}{l}\text { Statements are coded if the error is directly } \\
\text { addressed when speaking to colleagues/physicians. } \\
\text { Statements are not coded if there is no distinct } \\
\text { contact person. } \\
\text { Anchor example: 'Talk with a colleague and indicate } \\
\text { to him that an error has happened to him.' }\end{array}$ \\
\hline & $\begin{array}{l}\text { I, myself, am more } \\
\text { cautious in the future. }\end{array}$ & Personal learning & $\begin{array}{l}\text { Statements are coded where a personal perspective } \\
\text { resulting in a learning process is apparent. } \\
\text { Anchor example: 'I, myself am more cautious in the } \\
\text { future.' }\end{array}$ \\
\hline
\end{tabular}

The case vignette scenarios differed regarding three factors: the physician whose acts caused the error (self or other), the presence of witnesses (present or absent) and the consequences of the medical error for the patient (negative outcomes or no effects). By varying these factors, we ended up with an overall number of six different case vignette scenarios (see table 1 ). After reading the randomly assigned case scenario, the participant was asked the open question: 'What would you do?' The question was answered in a free-text field.

\section{Data analysis}

To answer the first research question, data were analysed using a descriptive qualitative content analysis approach according to Mayring. ${ }^{29}$ This process is illustrated in figure 1, showing the general step model of inductive category development.

The coding process in our study was performed by all four authors and can be described as follows: the raw material was defined as all written answers, the unit of analysis was defined as one answer. In terms of familiarisation with the raw material, all answers were read by three researchers (MK, IK and JK) as the first step. In the second step (paraphrasing), all passages that did not directly correspond to the research question were removed (eg, decorating, repeating or clarifying utterances). One paraphrase was defined as a coding unit. Subsequently, all four researchers met and developed a coding scheme based on $25 \%$ of the data material. The passage of the text that best reflected the category was chosen as an anchor example. Exclusion and inclusion criteria for each category were specified as coding rules. After the development of the coding scheme, it was applied to the whole material by researcher MK. Thus, all passages of the text were coded into the coding system.
To manage data, no specific software for qualitative data except Microsoft Word and Excel was used. To clarify the coding process, an excerpt of the coding scheme is shown in table 2.

To ensure quality of the coding process in terms of inter-rater reliability, a fifth researcher (TK, not part of the author team) independently coded $10 \%$ of the material. The inter-rater reliability for the categorical data was tested using the same coding scheme, resulting in a Fleiss $\kappa=0.84$, indicating sufficient agreement. ${ }^{30}$ At any time during the coding scheme's development and application none of the coders were aware to which case vignettes the unit of analysis belonged. Data saturation was discussed within the research team after development of the coding scheme, based on $25 \%$ of the data, and after finalisation of the coding process of all data. As all of the text's passages could be allocated to at least one of the categories that were defined by the coding scheme and no new categories had emerged while analysing the remainder $75 \%$ of the data, the researchers agreed that a sufficient saturation of data was reached for the purpose of the present study. Efforts were directed to examine both positive and negative cases; within the developed coding schema we were able to code all data.

In order to answer the second research question, the results were analysed distinguishing each case vignette scenario. The quantity of the categories that arose was counted, according to Wolcott's ${ }^{31}$ procedure for transforming qualitative data. We explored differences between scenarios, which varied depending on patient outcome, error witness and cause of error.

During the process of coding the data we tried to continually and critically self-evaluate our individual position and personality and we acknowledge that our 


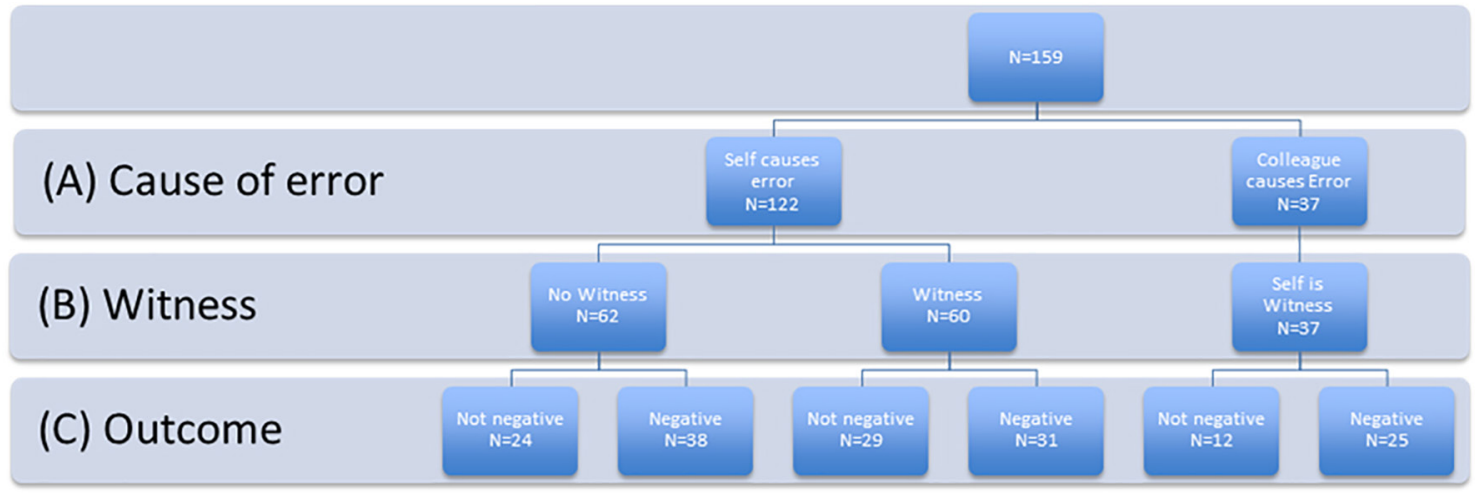

Figure 2 Study design and number of participants according to the cases.

position may affect the research process and outcome, as is common in qualitative research and discussed under the term reflectivity. ${ }^{32}$

\section{RESULTS}

\section{Description of the sample}

Altogether, $\mathrm{n}=320$ students opened the online survey and $n=159$ students answered a case vignette. Due to dropouts (ie, students who opened the survey and thus got randomly allocated to a scenario but did not answer it) the distribution of participants to cases is uneven. Figure 2 shows the number of respondents per scenario and per factor.

The participants were on average 24.6 years old $(\mathrm{SD}=7.9)$ and 110 of them $(69 \%)$ were female. The majority of the participants were in the third, fourth or fifth year of their studies $(n=107)$. Other students $(n=27)$ were in their first year and second year and $n=21$ participants were in their final year; for $n=4$ no information was available. ${ }^{i}$

\section{Categories}

For answering the first research question, during the inductive coding process the following 19 categories emerged from the original data (see table 2), clustered into four themes: (1) considering communication; (2) considering reporting; (3) considering consequences; and (4) emotional responsiveness.

\section{Considering communication}

Within the theme considering communication we subsumed nine categories. The categories apologise to the patient and disclosure of an error to the patient include quotes in which the student signals a strong intention to offer an apology or a disclosure to the patient:

After the surgery, I inform the patient about the mistake and apologize. (No. 92, scenario 4)

\footnotetext{
${ }^{\mathrm{i}}$ German undergraduate medical education can be divided into three parts: first and second years (preclinical years), where the focus is on basic sciences and biomedical knowledge; third, fourth and fifth years, where the focus is on knowledge regarding illnesses (clinical years); and the final year (practical year), which is a clinical rotation.
}

...tell her [the patient], that an image of the other hip was taken by accident... and apologize. (No. 13, scenario 2)

The category consideration to disclose covers coding units in which the student only considers disclosure or reflects on the possibility of telling the patient about the error, but is not sure of doing it.

Ideally, the correct reaction would be to tell the patient about the error and the resulting consequences in an explicit and understandable manner... (No. 44, scenario 4)

If I would know better about the consequences for me and how I would deal with them, I would be rather prepared to be honest with the patient. (No. 269, scenario 2)

The category consideration to not disclose contains statements where the student reflects rather on not informing the patient about the committed error:

I would not tell the patient about the mistake because it is no longer relevant. (No. 228, scenario 1)

...I am not sure if I would do that in a real case because I would be afraid to be sued... [I would] rather try to find a plausible excuse for the error or try to conceal it. (No. 44, scenario 4)

I can't rule-out that-in a bad team status/team climate-I would cover up the error. (No. 65, scenario 4)

In the category concealment, all the coding units in which the student is sure about keeping his knowledge about the error for himself are subsumed:

I shut my mouth and hope that no one notices. (No. 22, scenario 1)

I don't have the balls to admit my error-sad actually! (No. 122, scenario 1)

I would not disclose this to the patient and I would ensure that I make less errors. (No. 139, scenario 1)

Note that the categories disclosure of an error to the patient, considering disclosure, considering no disclosure and concealment are mutually exclusive to each other. 
Within the following categories statements are consolidated, in which the student describes that he intends to talk about the error with someone. The four categories are not mutually exclusive: communication with colleagues, communication with nursing staff, communication with the superior/chief and communication with others.

Most likely, I would try to discuss this medical error with a superior or colleague (regarding the further course of action). (No. 6, scenario 1)

I go to the respective colleague and discuss with him what we should do further; that is, first speaking with the senior physician or speaking directly to the team. (No. 55, scenario 6)

Discuss with colleagues and Boss (depending on the boss...) (No. 88, scenario 2)
Whether I would explain it to my boss, depends on my expectation of his reaction. (No. 228, scenario 1)

I would admit my error... [and] tell the nurses, X-ray technicians and other physicians that they should bring it to my attention when they notice one of my errors. (No. 18, scenario 1)

Discuss with all of those involved and superiors.

(No. 124, scenario 4)

Call-in a team meeting. (No. 255, scenario 4)

Considering reporting

The theme considering reporting contains an overall number of two categories. They differ from those in the first theme by including statements about reporting the error in a written format instead of oral communication.

Table 3 Descriptive overview of the categories in all the cases; percentage comparison refers to the proportion of participants who mentioned that category in reply to the characteristic of the case vignette scenarios

\section{Case vignette scenario}

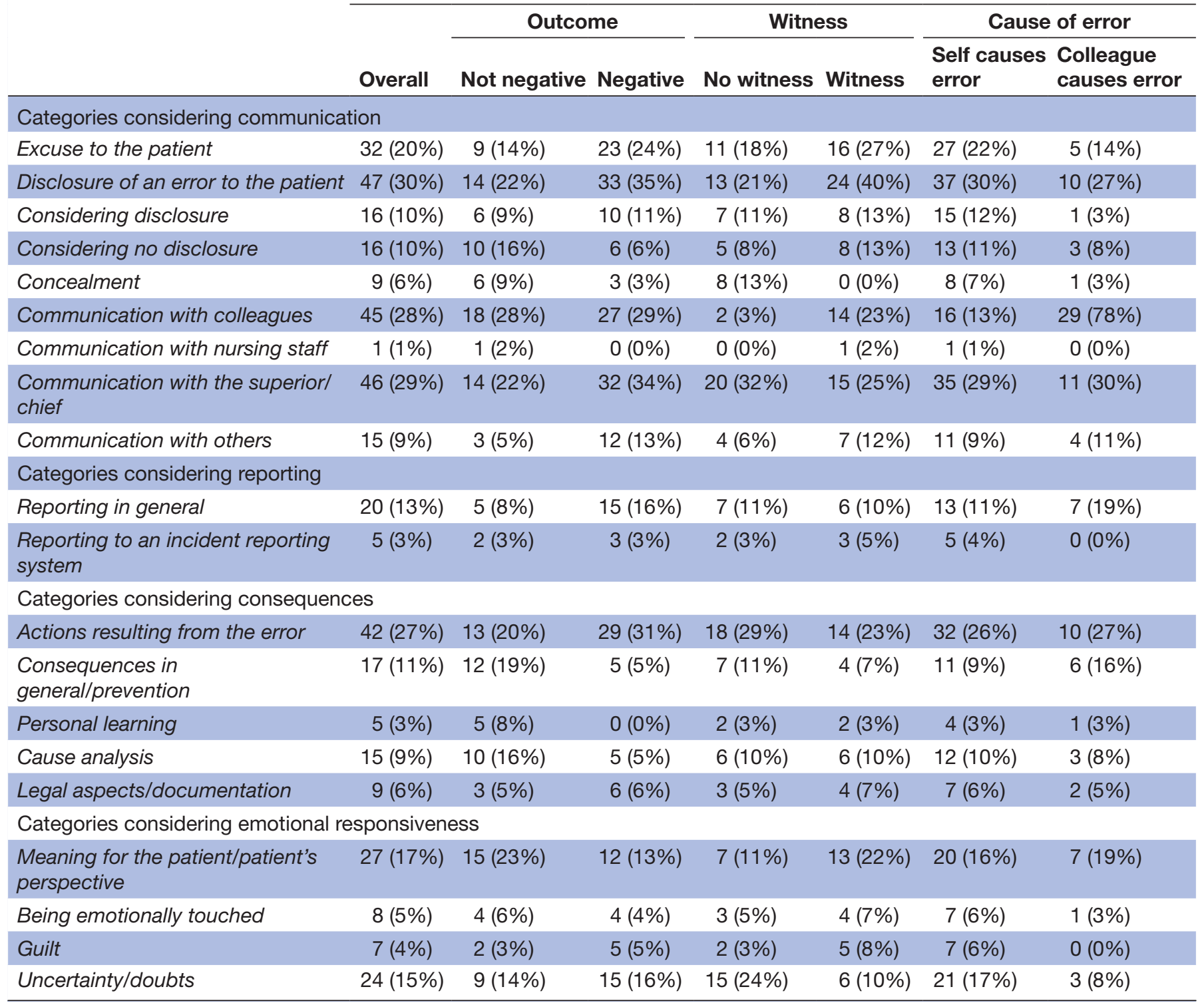


The category reporting in general covers statements in which the student explains that he would report the error but does not specify how he would do it, where he would report it, or to whom he would report it:

Then one must officially report this, I just don't know where. (No. 58, scenario 2)

If, additionally to the intention to report the error, the statement mentions a reporting system or equivalent structures, it is subsumed under the category reporting to an incident reporting system:

Report in the potentially existing error reporting system (ie, Critical Incident Reporting System). (No. 220, scenario 3)

Report in anonymous system. (No. 4, scenario 2)

[Give] info to the error management of the clinic.

(No. 206, scenario 3)

\section{Considering consequences}

The theme considering consequences consists of five categories describing the consequences of the error or the next steps that one will undertake. The category actions resulting from the error includes statements that picture concrete actions that have to follow the error from the students' perspective, such as:

Initiate respective therapy. (No. 48, scenario 4)

Immediately, when the error was noticed, I would call the patient back into the practice/clinic and x-ray the correct side. (No. 75, scenario 3)

Presumably, from now on, together with the patient, I would mark the extremity that I am supposed to x-ray with a marker. (No. 2, scenario 1)

If consequences other than a direct action were named or if the student reflects on a strategy for future prevention, the quote was assigned to the category consequences in general/prevention:

I would...see how to avoid it [the error] in the future. Then a solution strategy should be found and discussed with all involved wards. (No. 40, scenario 1)

...mention catastrophical state of the ER and, through the top supervisor, insist on better controls. (No. 90, scenario 2)

...it is about everyone learning from errors and reducing them, and reinforcing teamwork without any punishment. Employees should be encouraged to admit errors without any fear. (No. 155, scenario 2)

...revisit the case later and discuss in quality management so that colleagues can learn more from it. (No. 246, scenario 6)

The category personal learning covers statements that mention the conclusions that the student draws on for his or her own future actions:
I... am more sensitive towards this topic in the future so that such an error will not happen to me once again. (No. 132, scenario 3)

The learning effect would probably be really big for me and I would learn from this error. (No. 228, scenario 1)

If the search for causes leading to the error was described, quotations are subsumed to the category cause analysis:

I'd deliberate on how this error could have happened. Was it me making a wrong request? If so, why? Or, an incorrect execution by the X-ray nurse? If so, why? (No. 2, scenario 1)

I would conduct an error search and, firstly, see where the error occurred. (No. 40, scenario 1)

Talk with my colleague and ask him how this could have taken place. (No. 28, scenario 5)

Search the reason how this mix-up came to be... Deliberate the working process. (No. 117, scenario 3)

If students mentioned legal aspects or considered a special documentation, statements were subsumed in the category legal aspects/documentation:

I would inform her about her rights, even if this would be to my disadvantage. (No. 175, scenario 4)

Inform [her] about rights for damage compensation. (No. 177, scenario 4)

Because she [the patient] would lose a lot of time and nerves in a lawsuit, I would advise her to really ask herself whether that's what she wants in the case that she has this idea [to go to court] on her own. I am not a supporter of immediate lawsuits after errors in a medical procedure. (No. 232, scenario 6)

....if it must be, I would apologize. (Note: Of course it must be but I would be worried, for example, to then be sued.) (No. 269, scenario 2)

\section{Emotional responsiveness}

The theme emotional responsiveness contains four categories that cover a range of emotional reactions to the error. The category meaning for the patient/patients' perspective covers statements in which the student reflects on the meaning of the error or possible consequences for the patient or mentions the patient's perspective:

I think I would in this case first discuss with my senior physician before I would inform the patient and possibly unnecessarily worry [her]. (No. 7, scenario 1)

Make sure that my error really has no effect or damage with the patient. If this should be, I wouldn't tell the patient in order to not unnecessarily concern [the patient]. (No. 32, scenario 3)

I would explain the incident to the patient and pointout that this has really negative consequences for her. 
I would hope for the patient's understanding of the stress in the hospital. (No. 112, scenario 2)

The lady could die if I do not monitor the right hip (and if the kind lady is older, the additional radiation exposure is justifiable). (No. 118, scenario 1)

...ask her [the patient] whether she wants to continue to be treated by me or another physician, or go to another clinic. (No. 161, scenario 4)

The category being emotionally touched subsumes statements in which the student expresses his own emotions or feelings towards the situation:

I am happy that my error had no consequences for the patient. (No. 119, scenario 3)

I am relieved that there is no pathological finding in the right hip. (No. 122, scenario 1)

How lucky. I shut my mouth and hope that no one notices. (No. 22, scenario 1)

If the question of guilt is raised, the quote was grouped to the category guilt:

Obviously, I myself am guilty. (No. 188, scenario 4)

If my colleague notices an error but didn't say anything, he is also guilty. (No. 203, scenario 4)

Statements that describe the uncertainty and doubts of the student about how to handle the situation were arranged in the category uncertainty/doubts:

Quite honestly, I can-as I am at the beginning of my studies and have no patient or clinical experience whatsoever-not exactly imagine how I would react in this type of situation. (No. 21, scenario 2)

...so really I don't know what I should do. (No. 114, scenario 6)

If I know better about the consequences for me and the handling of it, I would be prepared to be honest with the patient. Admitting to an error is essentialbut at what price? (No. 269, scenario 2)

Currently, I don't know how one should handle errors-to whom to report? (No. 116, scenario 3)

...if she would not like to be operated by me and nobody else is on duty or available, I would be at a loss. (No. 110, scenario 2)

\section{Transformed qualitative data}

Regarding the overall frequency of codes, it showed that in total 406 quotes were coded (see table 2). Categories containing the largest numbers of quotes were disclosure of an error to the patient $(\mathrm{n}=47 ; 30 \%)$, communication with the superior/chef $(\mathrm{n}=46 ; 29 \%)$, communication with colleagues $(\mathrm{n}=45 ; 28 \%)$ and actions resulting from the error $(\mathrm{n}=42 ; 42 \%)$. Many students wrote quotes that were subsumed into categories considering communication with somebody else, rather than with the patient $(n=107)$. About half of the students made statements regarding the issue of disclosure of the error: overall $\mathrm{n}=77(56 \%)$ quotes were subsumed to one of the four categories comprising the topic (disclosure of an error to the patient, considering disclosure, considering no disclosure, concealment). Only a minority of the students $(\mathrm{n}=25 ; 16 \%)$ considered reporting the error, and only a few $(n=5 ; 3 \%)$ mentioned to report it in an incident reporting system. Categories considering emotional responsiveness contained proportionally few quotes $(\mathrm{n}=66 ; 41 \%)$ within meaning for the patient $(\mathrm{n}=27 ; 17 \%)$ were counted the most frequent.

\section{Comparison of the case vignette scenarios}

In order to answer the second research question, how (A) cause of error, (B) error witness and (C) patient outcome affect students' behavioural intentions, we consider table 3 and present the most outstanding results below. Table 3 shows a descriptive overview of the distribution of the categories over all the case scenarios. Percentages refer to the proportion of participants who mentioned the particular category in reply to the characteristic of the case vignette scenarios.

\section{Error cause}

When a colleague caused the error in the case vignette scenario, more students would communicate with the colleague ( $78 \%$ vs 13\%), take preventive action in general (16\% vs $9 \%)$ and report the error $(19 \%$ vs $11 \%)$ than when the student caused the error him/herself. For the scenarios in which the student caused the error himself, guilt $(6 \%$ vs $0 \%)$, uncertainty/doubts $(17 \%$ vs $8 \%)$ and excuse to the patient ( $22 \%$ vs $14 \%$ ) were reported more frequently than when a colleague caused the error.

\section{Error witness}

Scenarios in which a witness observed the error evoked more quotes concerning both disclosure to the patient (40\% vs 21\%) and emotional responsiveness towards the meaning for the patient (22\% vs $11 \%$ ) than those scenarios without a witness. Additionally, the categories concealment ( $0 \%$ vs $13 \%)$ and uncertainty/doubts about how to deal with the error (10\% vs $24 \%$ ) appeared less frequently in scenarios involving a witness than without a witness.

\section{Patient outcome}

If the outcome of the scenario was negative for the patient, more students mentioned disclosure of the error to the patient (35\% vs 22\%), communication to the superior/ chief (34\% vs 22\%), reporting of the error in general $(16 \%$ vs $8 \%)$ and actions resulting from the error $(31 \%$ vs $20 \%$ ) than when there were no negative outcomes for the patient.

In the scenarios in which the error did not have negative outcomes for the patient, students mentioned more often the consequences in general ( $19 \%$ vs $5 \%)$, personal learning ( $8 \%$ vs $0 \%)$, cause analysis $(15 \%$ vs $5 \%$ ) and meaning for the patient/patient's perspective (23\% vs $13 \%$ ) than when the patient suffered from the error. 


\section{DISCUSSION}

This study aimed at obtaining insight into medical students' behavioural intentions after having observed or having caused a hypothetical medical error. The qualitative analysis of students' written answers on how they would deal with a hypothetical error case scenario revealed four main themes: communication, reporting, consequences and emotional responsiveness.

We explored how students' behavioural intentions are influenced by three fundamental characteristics of the setting in which the error took place.

First, it showed that the behavioural intentions might be influenced by whether the error was made by oneself or not. When the student him/herself caused the error, the emotional responsiveness was more dominant, whereas when a colleague caused the error, students felt more inclined to communicate, to report the error and to take preventive actions. Second, our data suggest that the presence or absence of a witness influenced the students' intentions to communicate about the error, and also their emotional responsiveness. Students showed more empathy with the patients and more often intended to inform the patient about the error if a witness was present. With a witness present, students also were also more certain about how to deal with the error compared with situations in which nobody saw the error. Third, the outcomes of the error for the patient appeared to influence students' behavioural intentions. In the case of negative outcomes, attention was directed towards communication with the patient or the superior/chief, reporting the error and actions to limit the harm caused by error. Meanwhile, in cases in which the patient was not harmed, students used the error as a chance to improve the healthcare system and their own competences by analysing the causes of the error, reflecting on options for prevention and the meaning for the patient, as well as using the error for personal learning.

Our findings suggest students consider different ways to handle errors: there are those who react emotionally and are uncertain of what to do, and those who were able to express behavioural intentions targeting preventive actions. It seems that when students are involved in the generation of errors, the existing cognitively driven behavioural intentions become dominated by the emotional responsiveness. In this case, the students anticipate an emotional response, considering the meaning for a patient, are emotionally touched, even feel guilty and experience uncertainty. This ties to early work of William Osler who proposed that good physicians are somewhat detached from their patient's suffering in order to function well. ${ }^{33}$

This highlights the importance of establishing educational approaches for practically dealing with errors, while also coping with emotions caused by these special situations, preferably in the undergraduate medical education. The scarce evidence on patient safety courses shows that while protocols, algorithms and knowledge have an important part in preventing an error, they cannot prepare for the emotional response that comes with involuntarily harming a patient or being involved in an error. ${ }^{34}$ In this line, Patey and colleagues ${ }^{35}$ did not find a difference after a training for medical students about feelings when making errors. It seems that thus far, medical educators are not equipped in how to stimulate, teach or test emotional preparedness when facing negative consequences for the patient. In medical practice, the need for emotional preparedness becomes even more imperative. In a survey of over 3000 physicians in internal medicine, a majority had anxiety about future errors and their job-related stress increased, even when involved only in near misses. ${ }^{34}$ Apart from offering training approaches, the call for organisational accountability due to emotional impact on physicians has been emphasised. ${ }^{36}$ Even if emotional reactions in terms of empathy can be considered as an important skill for a physician, especially in those incidents where patients have suffered, changing protocols and taking actions for safer healthcare should be of high importance. ${ }^{7}$ Thus, both issues are important aspects that, according to the authors' opinion, have to be integrated and trained in patient safety curricula.

Students in our study also emphasised the importance of communication to the patient involved (ranging from disclosing to the patient, to considering not to disclose, to concealment), as well as talking about the error with colleagues, nurses, the superiors or others. This finding highlights the importance of courses including error disclosure for medical students, ${ }^{3537}$ and team communication courses. ${ }^{38-40}$ Hypothetical cases, like in the vignettes, or one's own cases could be discussed within group coaching sessions to enhance deep learning on (near) errors. ${ }^{41}$ The inclusion of the students' consideration of if and when to speak to their superiors depending on the (imagined) atmosphere within the team was especially interesting. In the literature, this resembles the construct of psychological safety, shown to be important for leader inclusiveness in healthcare. ${ }^{42}$ In his second assessment of progress in 10 key patient safety domains called 'Patient Safety At Ten: Unmistakable Progress, Troubling Gaps,' Wachter $^{43}$ states a drop in implementation rates of training initiatives, as only few organisations adopt robust teamwork, culture change or simulation programmes (ie refs 44 45). Some students intended to report the error to an incident reporting system, or otherwise in terms of sharing the error experience with the healthcare organisation, but did not know how to do so. This is in line with the finding of Toennessen $e t a l,{ }^{46}$ who have shown the need for more information concerning patient safety reporting. Further, it ties to the findings of Martinez and Lo, ${ }^{22}$ who showed that students who witnessed physicians take responsibility for errors and disclose errors to patients said that they aspired to these standards.

The various consequences of the error and of the actions students would intend to take included extra medical care for the patient and informing the patient about legal aspects, as well as learning from the error for future improvement. The latter contains cause analysis 
to better understand how the error could happen, plans or thoughts on how the error could be prevented and personal learning about individual knowledge and skills that may need improvement. ${ }^{47-49}$

Our results are in line with the findings that students generally have a positive attitude towards patient safety and are generally willing to participate in patient safety initiatives. ${ }^{11} 1920$ Our results underline that knowledge of what to do in the case of an error is limited for most students $\left(\mathrm{cf} \mathrm{ref}^{11}\right)$. We were able to gain more insight into the findings by Muller and Ornstein, ${ }^{24}$ who have shown that the more students were emotionally involved in the error, the more they were afraid of litigations. Our results add to this result that students generally have some knowledge on how to handle errors and have ideas whom to communicate to and did express the wish to disclose the error to the patient, as well as the wish to let the organisation and team learn from the error.

\section{Limitations}

One limitation of the study might be the transferability of our results, as our sample included German medical students only, and only German and Dutch researchers coded the data. Thus, other researchers need to take caution when interpreting the results and our findings should be confirmed in other countries and cultural settings .

Recruitment might have impacted our data as participation was voluntary and compensation was only small. Compensation might also have influenced the recruitment, but compensation was so limited that potentially only students interested in the subject participated.

Furthermore, not all participants were exposed to the same scenario, what might potentially reduce the richness of data. However, we chose our study design to expose differences in medical students' behavioural intentions through the different scenarios. The scenarios were originally developed for residents, but we piloted the scenarios on a smaller sample, and given the richness of the data we do believe they can also be used with medical students. In our sample, we neither differentiated between the years of study nor did we investigate the behavioural intentions of residents. There is a possibility that the final semester students' professionalism increases and more students would handle errors appropriately once the medical education programme is finished. Investigating the differences in behavioural intentions throughout the years of study would be an interesting focus for future research.

Although behavioural intention is more closely linked to behaviour than attitude, it is still not the actual behaviour and the link between both needs to be studied more deeply. However, if medical students do not know what to do and do not have any intention to perform a certain way in case of an error, the probability of showing appropriate behaviour is seen as highly unlikely. ${ }^{50}$ Further studies could potentially use the methodology of case vignettes with errors and give adaptive feedback depending on their free-text answers, ${ }^{51}$ that is, in order to convey norms of reporting, error disclosure and communication.

Last, we chose to do a quantitative transformation of the qualitative data to compare the influencing factors. Our conclusions are to be seen as observations from qualitative data and not to be confused with statistically sound comparisons of interval-scaled data.

\section{CONCLUSION}

By using standardised case vignettes and qualitative research methods, we are beginning to better understand the driving forces between anonymous reporting, error disclosure and concealment. Students need to understand that dealing with errors is part of being a physician. Medical educators need to understand that it is necessary to educate students in a way that they know exactly what to do when dealing with an error, and are equipped with effective coping strategies for dealing with strong emotions, so that they are enabled to adequately handle the situation.

Acknowledgements The authors are grateful for a grant from the Volkswagen Foundation during the manuscript preparation.

Contributors IK had the idea and took part in the design of the study, the data coding and analysis, and the drafting of the manuscript. KDK took part in the data coding and analysis and the drafting of the manuscript. MK took part in the design of the study, the data acquisition, coding and analysis of data, and the revision of the manuscript. JK took part in the design of the study, the data coding and analysis, and the drafting of the manuscript.

Funding The study was partly funded by a grant from the VolkswagenStiftung (№. 86966).

Competing interests None declared.

Patient consent Not required.

Ethics approval Ethics board of University Hospital of LMU Munich.

Provenance and peer review Not commissioned; externally peer reviewed. Data sharing statement No additional data available.

Open Access This is an Open Access article distributed in accordance with the Creative Commons Attribution Non Commercial (CC BY-NC 4.0) license, which permits others to distribute, remix, adapt, build upon this work non-commercially, and license their derivative works on different terms, provided the original work is properly cited and the use is non-commercial. See: http://creativecommons.org/ licenses/by-nc/4.0/

(c) Article author(s) (or their employer(s) unless otherwise stated in the text of the article) 2018. All rights reserved. No commercial use is permitted unless otherwise expressly granted.

\section{REFERENCES}

1. Moorthy K, Munz Y, Dosis A, et al. The effect of stress-inducing conditions on the performance of a laparoscopic task. Surg Endosc 2003;17:1481-4.

2. Truog RD, Browning DM, Johnson JA, et al; Talking with patients and families about medical error: a guide for education and practice: JHU Press, 2010.

3. Van der Schaaf TW, Lucas DA, Hale AR. Near miss reporting as a safety tool Butterworth-Heinemann, 2013.

4. Wu AW, Aw W. Medical error: the second victim. the doctor who makes the mistake needs help too. BMJ 2000;320:726.

5. Cronenwett L, Sherwood G, Barnsteiner J, et al. Quality and safety education for nurses. Nurs Outlook 2007;55:122-31.

6. Grube J. Health professions education: a bridge to quality, 2004. 
7. Wong BM, Etchells EE, Kuper A, et al. Teaching quality improvement and patient safety to trainees: a systematic review. Acad Med 2010;85:1425-39.

8. Association of American Medical Colleges. Joint Committee of the Group on Resident Affairs and Organization of Resident Representatives. Report on patient safety and graduate medical education. https://members.aamc.org/eweb/2003

9. Walton M, Woodward H, Van Staalduinen S, et al. The WHO patient safety curriculum guide for medical schools. Qual Saf Health Care 2010;19:542-6.

10. WHO. WHO Patient Safety Curriculum Guide for Medical Schools. 2009 http://www.who.int/patientsafety/education/curriculum/EN PSP_Education_Medical_Curriculum/en/index.html (Aufrufdatum 28 Apr 2013).

11. Flin R, Patey R, Jackson J, et al. Year 1 medical undergraduates knowledge of and attitudes to medical error. Med Educ 2009;43:1147-55.

12. Kiesewetter J, Gutmann J, Drossard S, et al. The Learning Objective Catalogue for Patient Safety in Undergraduate Medical Education-A Position Statement of the Committee for Patient Safety and Error Management of the German Association for Medical Education. GMS $J$ Med Educ 2016;33.

13. Kern D, Thomas P, Howard D, et al; Curriculum development for medical education. A six-step-approach. Baltimore: The John Hopkins University Press, 1998.

14. Venus E, Galam E, Aubert JP, et al. Medical errors reported by French general practitioners in training: results of a survey and individual interviews. BMJ Qual Saf 2012;21:279-86.

15. Varjavand N, Bachegowda LS, Gracely E, et al. Changes in intern attitudes toward medical error and disclosure. Med Educ 2012;46:668-77.

16. Mankaka CO, Waeber G, Gachoud D. Female residents experiencing medical errors in general internal medicine: a qualitative study. BMC Med Educ 2014;14:140.

17. Brasaite I, Kaunonen M, Martinkenas A, et al. Health care professionals' attitudes regarding patient safety: cross-sectional survey. BMC Res Notes 2016;9:177.

18. García Elorrio E, Macchiavello D, Rodriguez V, et al. Knowledge, beliefs and attitudes report on patient care and safety in undergraduate students: validating the modified APSQ-III questionnaire. Medwave 2016;16:e6809.

19. Madigosky WS, Headrick LA, Nelson K, et al. Changing and sustaining medical students' knowledge, skills, and attitudes about patient safety and medical fallibility. Acad Med 2006;81:94-101.

20. Kaldjian LC, Jones EW, Wu BJ, Bj W, et al. Disclosing medical errors to patients: attitudes and practices of physicians and trainees. $J$ Gen Intern Med 2007;22:988-96.

21. Benbassat J, Pilpel D, Schor R. Physicians' attitudes toward litigation and defensive practice: development of a scale. Behav Med 2001;27:52-60.

22. Martinez W, Lo B. Medical students' experiences with medical errors: an analysis of medical student essays. Med Educ 2008;42:733-41.

23. Godin G, Bélanger-Gravel A, Eccles M, et al. Healthcare professionals' intentions and behaviours: a systematic review of studies based on social cognitive theories. Implement Sci 2008;3:36.

24. Muller D, Ornstein K. Perceptions of and attitudes towards medical errors among medical trainees. Med Educ 2007;41:645-52.

25. Ritchie J, Lewis J, Nicholls CM, et al. Qualitative research practice: A guide for social science students and researchers. Sage 2013.

26. Kiesewetter J, Kager M, Lux R, et al. German undergraduate medical students' attitudes and needs regarding medical errors and patient safety-a national survey in Germany. Med Teach 2014;36:505-10.

27. In: Van Mierlo J, Vandersteen M, Van der Schaaf T, eds. The use of nursing and medical vignettes to measure attitudes and perceptions on patient safety. Leuven, Belgium: Nursing conference: building together on safe care, 2010.

28. Könings KD, Koopmans R, Van der Vleuten CPM, et al; Comprehensive learning effects of a course on patient safety. Lyon, France: Conference of the Association for Medical Education in Europe, 2012.

29. Mayring P. Qualitative content analysis: theoretical foundation, basic procedures and software solution, 2014.
30. Landis JR, Koch GG. The measurement of observer agreement for categorical data. Biometrics 1977;33:159-74.

31. Wolcott HF. Transforming qualitative data: description, analysis, and interpretation: Sage, 1994

32. Berger R. Now I see it, now I don't: researcher's position and reflexivity in qualitative research. Qualitative Research 2015;15:219-34

33. Osler W. The hospital as a college. Aequanimitas, with other addresses to medical students, nurses and practitioners of medicine, 1932:327-42.

34. Waterman AD, Garbutt J, Hazel E, et al. The emotional impact of medical errors on practicing physicians in the United States and Canada. Jt Comm J Qual Patient Saf 2007;33:467-76.

35. Patey R, Flin R, Cuthbertson BH, et al. Patient safety: helping medical students understand error in healthcare. Qual Saf Health Care 2007;16:256-9.

36. Schwappach DL, Boluarte TA. The emotional impact of medical error involvement on physicians: a call for leadership and organisational accountability. Swiss Med Wkly 2009;139:9.

37. Kiesewetter J. Simulationsbasiertes Teamtraining zum Umgang mit Behandlungsfehlern. In: Schmidt K, Verrel T, eds. Umgang mit Behandlungsfehlern im Krankenhaus. Münster: LIT-Verlag, 2012.

38. Lemieux-Charles L, McGuire WL. What do we know about health care team effectiveness? A review of the literature. Med Care Res Rev 2006;63:263-300.

39. Leonard M, Graham S, Bonacum D. The human factor: the critical importance of effective teamwork and communication in providing safe care. Qual Saf Health Care 2004;13(suppl 1):i85-i90.

40. Manser T. Teamwork and patient safety in dynamic domains of healthcare: a review of the literature. Acta Anaesthesiol Scand 2009;53:143-51.

41. Könings KD, van Berlo J, Koopmans $\mathrm{R}$, et al. Using a smartphone app and coaching group sessions to promote residents' reflection in the workplace. Acad Med 2016;91:365-70.

42. Nembhard IM, Edmondson AC. Making it safe: the effects of leader inclusiveness and professional status on psychological safety and improvement efforts in health care teams. J Organ Behav 2006;27:941-66.

43. Wachter RM. Patient safety at ten: unmistakable progress, troubling gaps. Health Aff 2010;29:165-73.

44. MacPhail A, Young C, Ibrahim JE. Workplace-based clinical leadership training increases willingness to lead: appraisal using multisource feedback of a clinical leadership program in regional Victoria, Australia. Leadership in Health Services 2015;28:100-18.

45. Saravo B, Netzel J, Kiesewetter J. The need for strong clinical leaders - Transformational and transactional leadership as a framework for resident leadership training. PLoS One 2017;12:e0183019.

46. Toennessen B, Swart E, Marx Y. [Patient safety culture - knowledge and knowledge needs of medical students]. Zentralb/ Chir 2013;138:650-6.

47. Bosk CL. Forgive and remember: managing medical failure: University of Chicago Press, 2003.

48. Dovey SM, Meyers DS, Phillips RL, et al. A preliminary taxonomy of medical errors in family practice. Qual Saf Health Care 2002;11:233-8.

49. Flores G, Laws MB, Mayo SJ, et al. Errors in medical interpretation and their potential clinical consequences in pediatric encounters. Pediatrics 2003;111:6-14.

50. Kennedy T, Regehr G, Rosenfield J, et al. Exploring the gap between knowledge and behavior: a qualitative study of clinician action following an educational intervention. Acad Med 2004:79:386-93.

51. Schulz C, Sailer M, Kiesewetter J, et al. Fallsimulationen und automatisches adaptives Feedback mittels Künstlicher Intelligenz in digitalen Lernumgebungen. 2017 https://www.e-teaching.org/ praxis/erfahrungsberichte/fallsimulationen-und-automatischesadaptives-feedback-mittels-kuenstlicher-intelligenz-in-digitalenlernumgebungen

52. Mayring P, Fenzl T. Qualitative inhaltsanalyse. Handbuch Methoden der empirischen Sozialforschung: Springer, 2014:543-56. 